\title{
Day-to-day discrepancy in Bravo pH monitoring is related to the degree of deterioration of the lower esophageal sphincter and severity of reflux disease
}

\author{
Shahin Ayazi - Jeffrey A. Hagen · Joerg Zehetner · Farzaneh Banki • \\ Florian Augustin - Ali Ayazi - Steven R. DeMeester • Daniel S. Oh • \\ Helen J. Sohn · John C. Lipham • Tom R. DeMeester
}

Received: 17 April 2010/Accepted: 9 September 2010/Published online: 27 February 2011

(C) The Author(s) 2011. This article is published with open access at Springerlink.com

\begin{abstract}
Background The Bravo capsule allows monitoring of esophageal acid exposure over a two-day period. Experience has shown that $24-32 \%$ of patients will have abnormal esophageal acid exposure detected on only one of the 2 days monitored. This variation has been explained by the effect of endoscopy and sedation. The aim of this study was to assess the day-to-day discrepancy following transnasal placement of the Bravo capsule without endoscopy or sedation and to determine factors related to this variability. Methods Bravo pH monitoring was performed by transnasal placement of the capsule in 310 patients. Patients were divided into groups based on the composite $\mathrm{pH}$ score: both days normal, both days abnormal and only one of the 2 days abnormal. Lower esophageal sphincter (LES) characteristics were compared between groups.

Results Of the 310 patients evaluated, 60 (19\%) showed a discrepancy between the 2 days. A total of 127 patients had a normal $\mathrm{pH}$ score on both days and $123 \mathrm{had}$ an abnormal $\mathrm{pH}$ score on both days. Of the 60 patients with a discrepancy, 27 were abnormal the first day and 33 (55\%) were abnormal the second day. Patients with abnormal
\end{abstract}

Presented at the 12th WCES, April 14-17, 2010, National Harbor, MD.

S. Ayazi · J. A. Hagen $(\bowtie) \cdot$ J. Zehetner · F. Banki ·

F. Augustin · S. R. DeMeester . D. S. Oh ·

H. J. Sohn - J. C. Lipham - T. R. DeMeester

Division of Thoracic Foregut Surgery, Department of Surgery,

Keck School of Medicine, University of Southern California,

1510 San Pablo Street, Suite 514, Los Angeles, CA 90033, USA

e-mail: hagen@surgery.usc.edu

A. Ayazi

Department of Electrical Engineering, University of California, Los Angeles, CA 90095, USA esophageal acid exposure on both days had higher degrees of esophageal acid exposure and were more likely to have a defective LES compared to those with an abnormal score on only one day (35 vs. $83 \%, p=0.027$ ).

Conclusion Patients with a discrepancy between days of Bravo $\mathrm{pH}$ monitoring have lower esophageal acid exposure. Variability between the 2 days represents early deterioration of the gastroesophageal barrier and indicates less advanced reflux disease.

Keywords Gastroesophageal reflux disease (GERD) . Esophagus · $\mathrm{pH}$ monitoring · Manometry ·

Wireless $\mathrm{pH}$ monitoring - Bravo capsule .

Esophageal motility · Lower esophageal sphincter (LES) . Discrepancy · Variability

The Bravo pH capsule (Given Imaging Inc., Duluth, GA) is a catheter-free system for ambulatory esophageal $\mathrm{pH}$ monitoring. An advantage of this system compared to a traditional nasoesophageal catheter is that it is more patient friendly and therefore allows measurement of esophageal acid exposure over a 48-h period. Previous reports have shown that $24-32 \%$ of patients have a discrepancy in acid exposure between the first and second 24-h monitoring periods [1-3]. It has been postulated that this discrepancy is related to the sedation used during endoscopic placement of the Bravo capsule, which may cause increased acid exposure early in the first 24-h monitoring period [4]. An alternative hypothesis is that some patients with gastroesophageal reflux disease (GERD) may have day-to-day variability in the amount of esophageal acid exposure. This hypothesis is supported by studies using the nasoesophageal $\mathrm{pH}$ catheter that showed a similar degree of discrepancy on repeated 24-h pH tests [5]. The aim of this study 
was to assess the discrepancy in acid exposure measured on day 1 and day 2 of Bravo $\mathrm{pH}$ monitoring following transnasal insertion and manometric placement of the $\mathrm{pH}$ capsule and to determine factors associated with this variability.

\section{Materials and methods}

From 2003 to 2007, 475 patients referred for evaluation of symptoms of GERD underwent ambulatory $\mathrm{pH}$ monitoring using the Bravo capsule. The study population included patients with no history of foregut surgery who had the Bravo $\mathrm{pH}$ capsule placed transnasally without sedation and who were monitored while off acid suppression therapy. A total of 310 patients met these criteria.

\section{Esophageal manometry}

All patients underwent esophageal manometry using a previously described technique [6]. In brief, a 12-French 8-channel water-perfused motility catheter (Arndorfer Medical Specialties, Greendale, WI) was passed through the anesthetized nostril after an overnight fast and the position of the lower esophageal sphincter (LES) in centimeters from the nostril was recorded using a commercially available software program (Polygram ${ }^{\circledR}$ Net, Medtronic Inc., Minneapolis, MN). Three manometric characteristics of the LES were assessed: resting pressure, total length, and abdominal length. The LES was considered defective when any or all of these components were abnormal [7].

Technique of measuring esophageal acid exposure

Patients were instructed to discontinue proton pump inhibitor medication 14 days and $\mathrm{H} 2$ blocker medication 3 days prior to $\mathrm{pH}$ monitoring and to avoid antacid medications during the study period. After an overnight fast, the Bravo delivery device and the attached $\mathrm{pH}$ capsule were inserted through an anesthetized nostril into the esophagus. The $\mathrm{pH}$ capsule was advanced into the stomach to measure gastric $\mathrm{pH}$ and then pulled back into the esophagus and deployed $5 \mathrm{~cm}$ above the manometrically determined upper border of the LES. Patients were asked to maintain a diary of symptoms and to record the time that they retired into bed in the evening and when they arose in the morning. They were instructed to remain in the upright or sitting position until retiring to bed in the evening and to lie flat at night if possible. They were asked to go about their normal duties at home or work. They were to refrain from eating or drinking between meals and avoid chewing gum and smoking. One meal during the study was standardized and consisted of a hamburger, fries, and milkshake obtained at a fast-food restaurant. The other meals were chosen from a list of foods with a pH between 5 and 7 . The meals were to be consumed at one sitting and accompanied only by water, milk, coffee, or tea. Carbonated beverages, alcohol, and fruit drinks with a low $\mathrm{pH}$ were not allowed. At the end of the recording period the data were downloaded from the recording unit to a personal computer for analysis using a commercially available software program (Polygram ${ }^{\circledR}$ Net, Medtronic Inc., Minneapolis, MN). Components of $\mathrm{pH}$ measurements and a composite $\mathrm{pH}$ score were used to express esophageal acid exposure [8].

Data analysis and statistical methods

Values are reported as median and interquartile range (IQR) unless otherwise indicated. Nonparametric tests were used to compare continuous variables and the $\chi^{2}$ test was used to compare categorical variables. The Spearman test was used to assess correlation, expressed as the correlation coefficient $R$ with $95 \%$ confidence intervals (CI). A $p$ value of less than 0.05 was considered statistically significant. Statistical analyses were performed using Prism 4 statistical software (Graphpad, San Diego, CA).

\section{Results}

The study population consisted of 158 males and 152 females with a median age of 52 years (IQR: 42-63). Esophageal acid exposure measured by Bravo $\mathrm{pH}$ monitoring on day 1 and day 2 are compared in Table 1 . Overall, there were no significant differences between day 1 and day 2 in any of the components or the composite $\mathrm{pH}$ score. There was good correlation between acid exposure measured on day 1 and day 2 for $\%$ total time $\mathrm{pH}<4$ and the composite $\mathrm{pH}$ score (Fig. 1). The composite $\mathrm{pH}$ score was normal on both days in 127 patients (41\%) and abnormal on both days in 123 patients (40\%). The score was abnormal on only one of the 2 days in 60 patients (19\%). In patients who were abnormal on only 1 day, 55\% had the abnormal composite $\mathrm{pH}$ score on the second day. In patients who were abnormal on both days, the composite $\mathrm{pH}$ score was higher on day 2 in 54\%. These differences were not statistically significant $(p=0.71$ and $p=0.70$, respectively).

To evaluate the severity of reflux in patients with an abnormal composite $\mathrm{pH}$ score on only 1 day and those with an abnormal $\mathrm{pH}$ score on both days, we compared the frequency of abnormality for each of the components of $\mathrm{pH}$ monitoring and the individual values for these components from the worst day of reflux, defined as the day with the highest composite $\mathrm{pH}$ score. Patients who had an abnormal 
Table 1 Comparison of esophageal acid exposure on day 1 and day 2 in all patients $(n=310)$

\begin{tabular}{lcll}
\hline & Day 1 & Day 2 & $p$ value $^{\mathrm{a}}$ \\
\hline \% Total time $\mathrm{pH}<4$ & $3.7(1.0-9.9)$ & $4.5(0.9-9.7)$ & 0.1679 \\
$\%$ Upright time $\mathrm{pH}<4$ & $4.5(1.2-12.1)$ & $4.8(1.0-11.5)$ & 0.5238 \\
\% Supine time $\mathrm{pH}<4$ & $0.3(0.0-5.9)$ & $0.3(0.0-6.30)$ & 0.4963 \\
$\begin{array}{l}\text { Number of reflux } \\
\text { episodes }\end{array}$ & $39(13-74)$ & $36(14.5-76)$ & 0.5746 \\
$\begin{array}{l}\text { Number of episodes } \\
\quad \geq 5 \text { min }\end{array}$ & $2(0-7)$ & $2(0-7)$ & 0.3869 \\
$\begin{array}{l}\text { Longest reflux episode } \\
\quad(\text { min })\end{array}$ & $10(3-25)$ & $9.0(3.0-21.5)$ & 0.3006 \\
Composite pH score & $13.1(4.7-32.0)$ & $14.4(3.9-30.5)$ & 0.6552 \\
\hline
\end{tabular}

${ }^{a}$ Wilcoxon matched pairs test

A

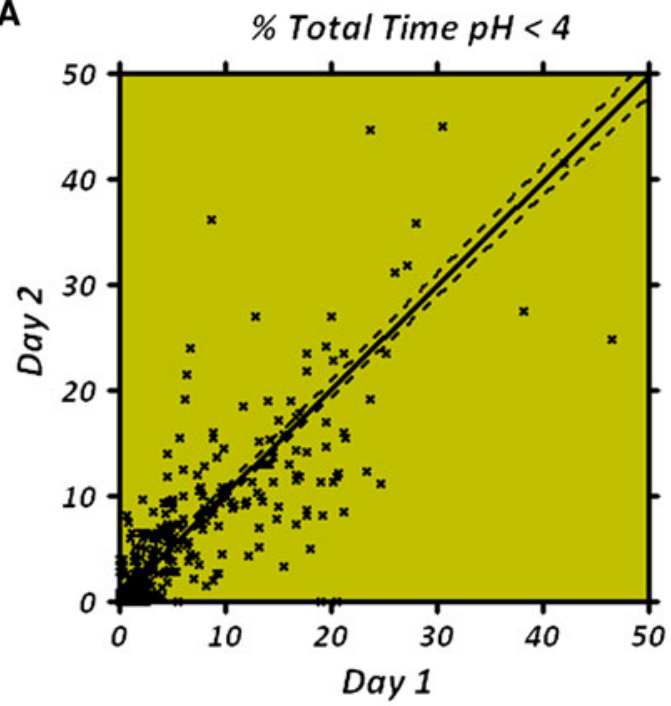

B

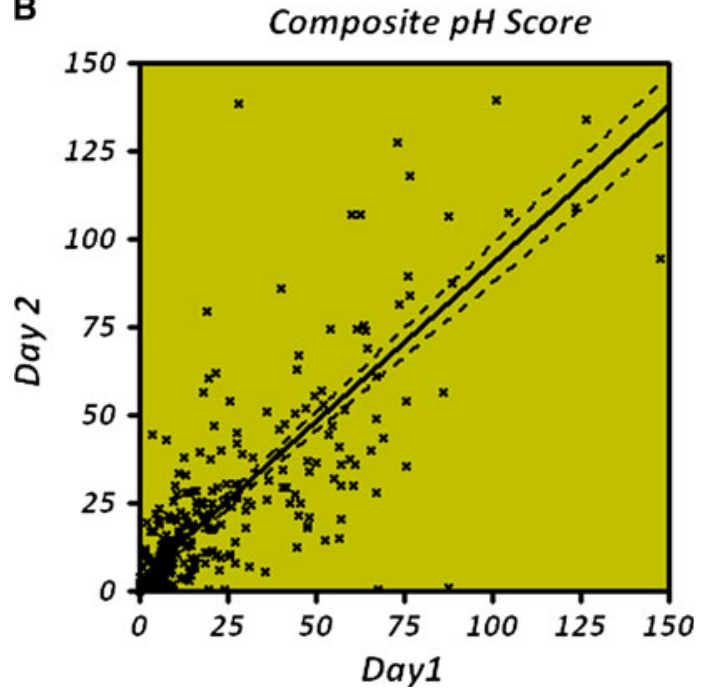

Fig. 1 Correlation between day 1 and day 2 for $\mathbf{A} \%$ total time $\mathrm{pH}<4$ and $\mathbf{B}$ composite $\mathrm{pH}$ score. The Spearman $R$ correlation coefficients were $0.94(95 \% \mathrm{CI}=0.93-0.95, \quad p<0.0001)$ and $0.83(95 \%$ $\mathrm{CI}=0.79-0.86, p<0.0001)$, respectively score on both days had a higher frequency of abnormality for each of the individual components (Fig. 2) and more severe reflux confirmed by each of the six components and the composite $\mathrm{pH}$ score (Table 2). Patients were divided into ten groups of equal size ( 31 in each group) based on the composite $\mathrm{pH}$ score on day 1 , and the percentage of patients with a discrepancy between day 1 and day 2 is plotted in Fig. 3. Patients with a composite $\mathrm{pH}$ score less than 8.7 and greater than 19.3 on day 1 had a low likelihood of discrepancy.

There was a progressive decrease in LES length and resting pressure starting with patients who were normal on both days, followed by those who were abnormal on only 1 day, and ending with those who were abnormal on both days (Table 3). There was also a progressive increase in the prevalence of a defective LES (Fig. 4) and the number of defective components (Table 4) when patients who were normal on both days, those who were abnormal on only 1 day, and those who were abnormal on both days were compared.

\section{Discussion}

Ambulatory $\mathrm{pH}$ monitoring when properly performed is a critical tool in the management of patients suspected of having GERD. Until recently this required a $\mathrm{pH}$ catheter placed through the nose for $24 \mathrm{~h}$ causing discomfort, social embarrassment, and restriction of patient activity during the monitored periods [9]. This could lead to underestimation of the amount of esophageal acid exposure that would occur under more typical lifestyle circumstances. With the introduction of the catheter-free Bravo $\mathrm{pH}$

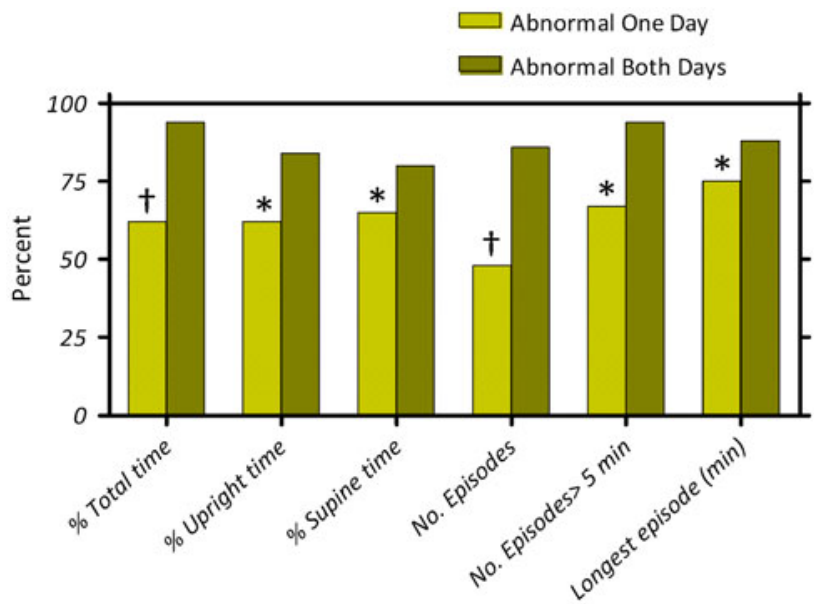

Fig. 2 Frequency of an abnormal component on the worst day of reflux in patients with a positive score on only one day and those with a positive score on both days. There was a significant difference for each individual component $\left(\dagger p<0.01,{ }^{*} p<0.05\right.$, Fisher's exact test) 
Table 2 Comparison of the worst day of reflux between patients with an abnormal composite score on only one day and those with an abnormal score on both days

\begin{tabular}{lllr}
\hline Components & $\begin{array}{l}\text { Abnormal score on } \\
\text { one day }(n=60)\end{array}$ & $\begin{array}{l}\text { Abnormal score on } \\
\text { both days }(n=123)\end{array}$ & $p$ value* \\
\hline$\%$ Total time $\mathrm{pH}<4$ & $6.3(4.7-8.2)$ & $15.1(10.2-21.4)$ & $<0.0001$ \\
$\%$ Upright time $\mathrm{pH}<4$ & $7.3(4-9.8)$ & $15.6(9.6-23.2)$ & $<0.0001$ \\
$\%$ Supine time $\mathrm{pH}<4$ & $4.6(0.2-7.6)$ & $14.1(3-28.2)$ & $<0.0001$ \\
Number of reflux episodes & $46(29-65)$ & $91.5(65.5-136)$ & $<0.0001$ \\
Number of episodes $\geq 5$ min & $3(2-6)$ & $10(6-14)$ & $<0.0001$ \\
Longest reflux episode $(\min )$ & $17.5(12-35.5)$ & $28.5(16.5-95)$ & 0.0004 \\
Composite $\mathrm{pH}$ Score & $20.7(16.5-26.3)$ & $50.2(30.5-69)$ & $<0.0001$ \\
\hline
\end{tabular}

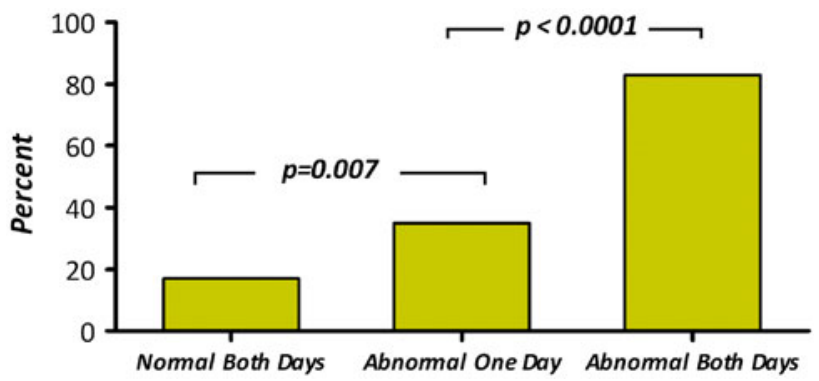

Fig. 4 The prevalence of a defective LES in patients with a normal score on both days (17\%), an abnormal score on only one day (35\%), and an abnormal score on both days $(83 \%)(p<0.0001$ across all three groups) (31 in each group) based on the composite $\mathrm{pH}$ score on day 1 , and the percentage of patients with a discrepancy between day 1 and day 2 is plotted. Fifty-one percent of patients with a $\mathrm{pH}$ score between 8.7 and 19.3 on the first day had a discrepancy between day 1 and day 2 . In contrast, of those who had a pH score of $<8.7$ or $>19.3$ on their first day of monitoring, only $11 \%$ had a day-to-day discrepancy

capsule, these limitations are avoided. Patients have no social embarrassment, less discomfort, and less interference with activities of daily living [1].

These advantages of the Bravo capsule allow monitoring of esophageal $\mathrm{pH}$ for longer periods of time. In practice, patients are commonly monitored for $48 \mathrm{~h}$ and esophageal acid exposure is calculated separately for the first and second day and for the combined $48 \mathrm{~h}$. Clinical experience has shown that approximately $25-30 \%$ of patients will have abnormal esophageal acid exposure detected on only one of the 2 days of monitoring [1-3]. Our previous work has shown that patients who have an abnormal composite $\mathrm{pH}$ score on either day should be considered to have increased esophageal acid exposure and reflux disease [10].

The reason for a discrepancy between the 2 days of monitoring is incompletely understood. One proposed explanation is that endoscopy and sedation encourage reflux [11]. Because of this, it has been suggested that the first $6 \mathrm{~h}$ of recording after sedation and endoscopic placement of the $\mathrm{pH}$ capsule should be excluded [4]. With this exclusion, Bhat et al. [4] reported better agreement of the results of the 2 days of monitoring but there were still a significant number of patients with a discrepancy in the results on day 1 and day 2 . It appears that their rate of discrepancy after excluding the first $6 \mathrm{~h}$ is similar to the $19 \%$ rate of discrepancy in our series of patients who had the capsule placed transnasally without sedation. An alternative explanation is that there are differences in the severity of reflux disease between patients who are abnormal on only 1 day and those who are abnormal on both days. Our results support this hypothesis. Patients who were abnormal on only 1 day had lower levels of esophageal acid exposure by all components measured, and their composite $\mathrm{pH}$ score was also significantly lower (21 vs. 50) when compared to those who were abnormal on both days.
Table 3 Resting characteristics of the LES $(n=310)$

* Kruskal-Wallis test

\begin{tabular}{lcclr}
\hline & $\begin{array}{l}\text { Normal score on } \\
\text { both days }(n=127)\end{array}$ & $\begin{array}{l}\text { Abnormal score on } \\
\text { one day }(n=60)\end{array}$ & $\begin{array}{l}\text { Abnormal score on } \\
\text { both days }(n=123)\end{array}$ & $p$ value* \\
\hline Overall length $(\mathrm{cm})$ & $2.9(2.4-3.6)$ & $2.7(2.2-3.4)$ & $2.3(1.6-3.2)$ & 0.0002 \\
Abdominal length $(\mathrm{cm})$ & $1.8(1.4-2.3)$ & $1.6(1.0-2.0)$ & $1.2(0.8-1.8)$ & $<0.0001$ \\
Resting pressure $(\mathrm{mmHg})$ & $14.9(10.2-23.7)$ & $13.7(8.7-18.3)$ & $9.2(5.5-15.0)$ & $<0.0001$ \\
\hline
\end{tabular}


Table 4 Frequency of abnormal LES resting characteristics $(n=310)$

\begin{tabular}{lllll}
\hline & $\begin{array}{l}\text { Normal score on } \\
\text { both days }(n=127)\end{array}$ & $\begin{array}{l}\text { Abnormal score on } \\
\text { one day }(n=60)\end{array}$ & $\begin{array}{l}\text { Abnormal score on } \\
\text { both days }(n=123)\end{array}$ & $p$ \\
\hline No defective components & $105(83 \%)$ & $39(65 \%)$ & $21(17 \%)$ & $<0.0001^{*}$ \\
\hline One defective component & $15(12 \%)$ & $13(22 \%)$ & $45(36 \%)$ & \\
Two defective components & $7(5 \%)$ & $6(10 \%)$ & $39(32 \%)$ & $18(15 \%)$ \\
Three defective components & $0(0 \%)$ & $2(3 \%)$ & & \\
\hline
\end{tabular}

* $\chi^{2}$ test

\section{References}

These findings are consistent with the observations of Wiener et al. [5] who performed repeat catheter-based 24-h esophageal $\mathrm{pH}$ monitoring. They found that there was a low probability of inconsistent results between the two monitoring periods in normal subjects and in those with severe reflux disease (defined as a total time $\mathrm{pH}<4$ above $9.4 \%$ ), but in patients with milder degrees of reflux there was a higher probability of having inconsistent results [5]. In our series, the highest likelihood of a discrepancy between day 1 and day 2 occurred in patients with a $\mathrm{pH}$ score on the first day between 8.7 and 19.3 , where $51 \%$ had a discrepancy. Patients with milder degrees of reflux and those with the most severe reflux were much less likely (11\%) to have a discrepancy between day 1 and day 2 .

In addition to having less severe reflux disease, patients with a discrepancy between the 2 days of Bravo monitoring also had less severe physiologic abnormalities on manometry. The overall length of the LES and the resting LES pressure were significantly greater in patients who were abnormal on only 1 day compared to patients who were abnormal on both days. Furthermore, patients that were abnormal on only 1 day were more likely to have a manometrically normal LES compared to those who were abnormal on both days.

In conclusion, when Bravo $\mathrm{pH}$ monitoring is performed with transnasal placement of the $\mathrm{pH}$ capsule, thus eliminating the effect of endoscopy and sedation, a discrepancy between the results measured on day 1 and day 2 is less but still exists. Factors associated with this discrepancy are the severity of the esophageal acid exposure and the degree of competency of the lower esophageal sphincter. Variability between the 2 days of monitoring represents early deterioration of the gastroesophageal barrier and indicates less advanced reflux disease.

Disclosures Dr. Tom DeMeester is on the scientific advisory board of Respiratory Technology Corp. and of Torax Medical Inc. Drs. Ayazi, Hagen, Zehetner, Augustin, Oh, Sohn, S. DeMeester, and Lipham have no conflicts of interest or financial ties to disclose.

Open Access This article is distributed under the terms of the Creative Commons Attribution Noncommercial License which permits any noncommercial use, distribution, and reproduction in any medium, provided the original author(s) and source are credited.
1. Pandolfino JE, Richter JE, Ours T, Guardino JM, Chapman J, Kahrilas PJ (2003) Ambulatory esophageal pH monitoring using a wireless system. Am J Gastroenterol 98(4):740-749

2. Tseng D, Rizvi AZ, Fennerty MB, Jobe BA, Diggs BS, Sheppard BC, Gross SC, Swanstrom LL, White NB, Aye RW, Hunter JG (2005) Forty-eight-hour $\mathrm{pH}$ monitoring increases sensitivity in detecting abnormal esophageal acid exposure. J Gastrointest Surg 9(8):1043-1051; discussion 1051-1052

3. Ahlawat SK, Novak DJ, Williams DC, Maher KA, Barton F, Benjamin SB (2006) Day-to-day variability in acid reflux patterns using the BRAVO $\mathrm{pH}$ monitoring system. J Clin Gastroenterol 40(1):20-24

4. Bhat YM, McGrath KM, Bielefeldt K (2006) Wireless esophageal $\mathrm{pH}$ monitoring: new technique means new questions. J Clin Gastroenterol 40(2):116-121

5. Wiener GJ, Morgan TM, Copper JB, Wu WC, Castell DO, Sinclair JW, Richter JE (1998) Ambulatory 24-hour esophageal pH monitoring. Reproducibility and variability of $\mathrm{pH}$ parameters. Dig Dis Sci 33(9):1127-1133

6. Zaninotto G, DeMeester TR, Schwizer W, Johansson KE, Cheng SC (1988) The lower esophageal sphincter in health and disease. Am J Surg 155(1):104-111

7. Ayazi S, Hagen JA, Chan LS, DeMeester SR, Lin MW, Ayazi A, Leers JM, Oezcelik A, Banki F, Lipham JC, DeMeester TR, Crookes PF (2009) Obesity and gastroesophageal reflux: quantifying the association between body mass index, esophageal acid exposure, and lower esophageal sphincter status in a large series of patients with reflux symptoms. J Gastrointest Surg 13(8):1440-1447

8. Ayazi S, Leers JM, Oezcelik A, Abate E, Peyre CG, Hagen JA, DeMeester SR, Banki F, Lipham JC, DeMeester TR, Crookes PF (2009) Measurement of gastric $\mathrm{pH}$ in ambulatory esophageal $\mathrm{pH}$ monitoring. Surg Endosc 23(9):1968-1973

9. Fass R, Hell R, Sampliner RE, Pulliam G, Graver E, Hartz V, Johnson C, Jaffe P (1999) Effect of ambulatory 24-hour esophageal $\mathrm{pH}$ monitoring on reflux-provoking activities. Dig Dis Sci 44(11):2263-2269

10. Ayazi S, Lipham JC, Portale G, Peyre CG, Streets CG, Leers JM, Demeester SR, Banki F, Chan LS, Hagen JA, Demeester TR (2009) Bravo catheter-free $\mathrm{pH}$ monitoring: normal values, concordance, optimal diagnostic thresholds, and accuracy. Clin Gastroenterol Hepatol 7(1):60-67

11. Bechtold ML, Holly JS, Thaler K, Marshall JB (2007) Bravo (wireless) ambulatory esophageal $\mathrm{pH}$ monitoring: How do day 1 and day 2 results compare? World J Gastroenterol 13(30): $4091-4095$ 